\title{
Monitoring Temporal Change of River Islands in the Yangtze River by Remotely Sensed Data
}

\author{
Jinyan Sun ${ }^{1,2}$, Lei Ding ${ }^{3}$, Jiaze $\mathrm{Li}^{4}$, Haiming Qian ${ }^{1,5}$, Mengting Huang ${ }^{1,2}$ and $\mathrm{Nan} \mathrm{Xu}^{6, *}$ \\ 1 Anhui \& Huaihe River Institute of Hydraulic Research, Hefei 230088, China; sun.jinyan@outlook.com (J.S.); \\ qianhaiming0520@sina.cn (H.Q.); HMT.M@outlook.com (M.H.) \\ 2 Anhui Province Key Laboratory of Water Conservancy and Water Resources, Hefei 230088, China \\ 3 Nanjing Hydraulic Research Institute, Key Laboratory of Port, Waterway and Sedimentation Engineering of \\ the Ministry of Transport, Nanjing 210029, China; hhudinglei@126.com \\ 4 Saint-Venant Laboratory for Hydraulics, EDF-Recherche et Développement, Laboratoire Saint-Venant \\ (EDF R\&D, CETMEF, Ecole des Ponts ParisTech), Chatou 78401, France; 1.jiazelu@gmail.com \\ 5 Anhui Dayu Project Construction Supervision and Consult Co., Ltd., Hefei 230088, China \\ 6 Department of Earth System Science, Tsinghua University, Beijing 100084, China \\ * Correspondence: xun14@mails.tsinghua.edu.cn; Tel.: +86-150-1096-3820
}

Received: 8 September 2018; Accepted: 18 October 2018; Published: 21 October 2018

\begin{abstract}
The spatial extent and area of river islands are always changing due to the impact of hydrodynamic conditions, sediment supply and human activities. A catastrophic flood disaster was driven by sustained and heavy rainfall around the middle and lower Yangtze River in 18 June to 21 July 2016. The flood resulted in the most serious social-economic loss since 1954 and caused a larger-scale inundation for a short time. It is essential to continuously monitor the dynamics changes of river islands because this can avoid frequent field measurements in river islands before and after flood disasters, which are helpful for flood warning. This paper focuses on the temporal change of three river islands called Fenghuangzhou, Changshazhou, and one uninhabited island in the Yangtze River in 2016. In this study, GF-1 (GaoFen-1) WFV (wide field view) data was used for our study owing to its fine spatial and temporal resolution. A simple NDWI (Normalized Difference Water Index) method was used for the river island mapping. Human checking was then performed to ensure mapping accuracy. We estimated the relationship between the area of river islands and measured water levels using four models. Furthermore, we mapped the spatial pattern of inundation risk of river islands. The results indicate a good ability of the GF-1 WFV data with a 16-m spatial resolution to characterize the variation of river islands and to study the association between flood disaster and river islands. A significantly negative but nonlinear relationship between the water level and the area of the river island was observed. We also found that the cubic function fits best among three models $\left(R^{2}>0.8, P<0.001\right)$. The maximum of the inundated area at the river island appeared in the rainy season on 8 July 2016 and the minimum occurred in the dry season on 28 December 2016, which is consistent with the water level measured by the hydrological station. Our results derived from GF-1 data can provide a useful reference for decision-making of flood warning, disaster assessment, and post-disaster reconstruction.
\end{abstract}

Keywords: river island; temporal change; water level; the Yangtze River

\section{Introduction}

The middle and lower reaches of the Yangtze River have developed a certain number of river islands, which have an important influence on the stability of the Yangtze River [1,2]. More attention should be paid to these islands because they make the flood control problem of the island reach more 
complicated. River islands exhibit various shapes and different surface areas. They are molded river sediment formed by continuous scouring and silting. Generally, flow action can result in the erosion of the head of a river island. Sediment deposition occurs at its tail where shoals are born. The island divides a river into multiple channels and forms the connection of interrelation and interaction between two channels [3,4]. Therefore, river islands can provide information on active processes and the sediment regime at the reach scale and are employed for geomorphic and sediment assessments for rivers worldwide [5-7]. They are also an important component of the morphodynamics of a river and are widely used to investigate the dynamics of flow regime [8-12]. The formation and development of river islands are important for better understanding of fluvial processes and their controlling factors. Thus, the study of temporal variation of river islands is a significant body of work.

River floods are considered to be the dominant force in shaping island morphology, as their power and kinetic energy are very high [13]. This is especially so for the monsoon-affected Yangtze River, where fluvial geomorphic work is largely carried out during monsoon floods [14]. Affected by long-term river erosion and sediment deposition, the rapidly evolving river island can significantly affect the waterway and flood control safety and threatens the production and life of people on both sides of the Yangtze River [15-20]. To maintain shipping conditions and ensure the safety of the people, the Chinese government has carried out many projects to strengthen river embankments and rectify river courses [21-23]. Limited by flood control and drainage capacity, a catastrophic flood disaster caused by sustained and heavy rainfall happened in the middle and lower Yangtze River in 2016 [24]. This river flood caused huge social-economic losses to Anhui province, second only to the 1954 flood [25] (pp. 29, 30, and 71), which also had a potential impact on river islands [26]. Therefore, it is necessary to grasp the changes of river islands before and after flood disasters and provide a scientific basis for river embankment reinforcement and river regulation. Remote sensing is a powerful tool for continuously monitoring dynamic changes of the river island, because it can provide large-scale, high spatial-temporal images [27-29]. Some scholars studied the area changes of river islands. Shi et al. [30] examined the long-term evolution of seven bars in the lower Yangtze River and found that the total area of bars decreased over time, with sediment and river discharge. Yang et al. [31] found the variations of low-water level have a relationship with river bed evolution. Wang et al. [32] analyzed four river islands in the middle Yangtze River from the Landsat data (30 m) in the flooding season of 2002. They found that two of the islands tended to be stable, while the other two experienced severe erosion during the flood. Those islands can also be large sediment sources rather than depositional areas during the flood. The decrease of sediment load in the middle of the Yangtze River was found to be responsible for the dramatic morphodynamics of river islands, which could last for a long period of time, depending on the operation of the Three Gorges Dam, which opened in 2003. Lou et al. [33] explored mid-channel bars evolution in the middle and lower reach of the Yangtze River and their responses to the Three Gorges Dam, the world's largest hydrological engineering project. Chen et al. [34] extracted water information of Shangri-la County's wetland from ETM+ (Enhanced Thematic Mapper) images using the threshold value method, interpolation method and spectral relationship method and found that the threshold value method cannot distinguish the mountain shadow and water easily. The use of remote sensing technology to obtain accurate and timely spatial range of river islands helps to avoid frequent on-site measurements of river islands before and after flood disasters. Bates et al. [35] studied a two-dimensional finite element model applied to the Missouri River, Nebraska and compared with a synchronous Landsat TM (Thematic Mapper) image of flood inundation extent. Godoy et al. [36] mapped fluvial islands using images from the Landsat 5 between 1988 and 2010 showed that the existing islands in the estuary suffered great changes during this period. Most of the above work was carried out either through experimental and theoretical studies or was focused on long-term investigations. The spatial resolution of remotely sensed data in the above studies ranged from $30 \mathrm{~m}$ to $250 \mathrm{~m}$. To date, few studies have detected the abrupt change of river islands in response to a single flood event. Moreover, it is essential to uncover the relationship between the area of river islands and the water level, and the response of river islands to a major river flood. 
This paper focuses on the temporal change of three river islands within the lower Yangtze River in 2016. Compared with other satellites, Chinese GF-1 (GaoFen-1) satellite has a short revisit period (only 4 days) and a high spatial resolution (16-m). Therefore, this study mainly uses GF-1 data, supplemented by other satellite data, such as Sentinel-2, Chinese GF-4 (GaoFen-4) data. The paper is organized as follows. The study area, remotely sensed data and hydrological data description are presented in Section 2. Methods is described in Section 3, results and analysis are presented in Section 4. The conclusion is given in Section 5.

\section{Data}

\subsection{Study Area}

The Yangtze River (also known as the Changjiang River) is the world's third longest river and the longest one in Asia. The Yangtze River basin is a typical monsoon climate zone, where rainfall is concentrated in the summer and autumn. The average annual rainfall is about $1100 \mathrm{~mm}$ in the Yangtze River basin, and more than $70 \%$ of the annual rainfall occurred from April to October. The river island is abundant in the Yangtze River. Among them, the larger river island generally has fixed villages and townships, such as Fenghuangzhou and Changshazhou. This paper selected three river islands Fenghuangzhou, Changshazhou and the uninhabited island as an example (Figure 1). These river islands are located in the Anhui reach which at the lower reaches of the Yangtze River. Fenghuangzhou (also known as Fengyizhou) has formed a shoal in the Song Dynasty (960 A.D. 1279 A.D.). The embankment was built on the early Qing Dynasty (1650 A.D. 1670 A.D.). There are more than 8000 people living on Fenghuangzhou, with planting cotton, corn, and vegetables, and breeding [37]. Near the Fenghuangzhou, Changshazhou has more than six thousand people, who plant cotton, corn, and poplars for a living [38].

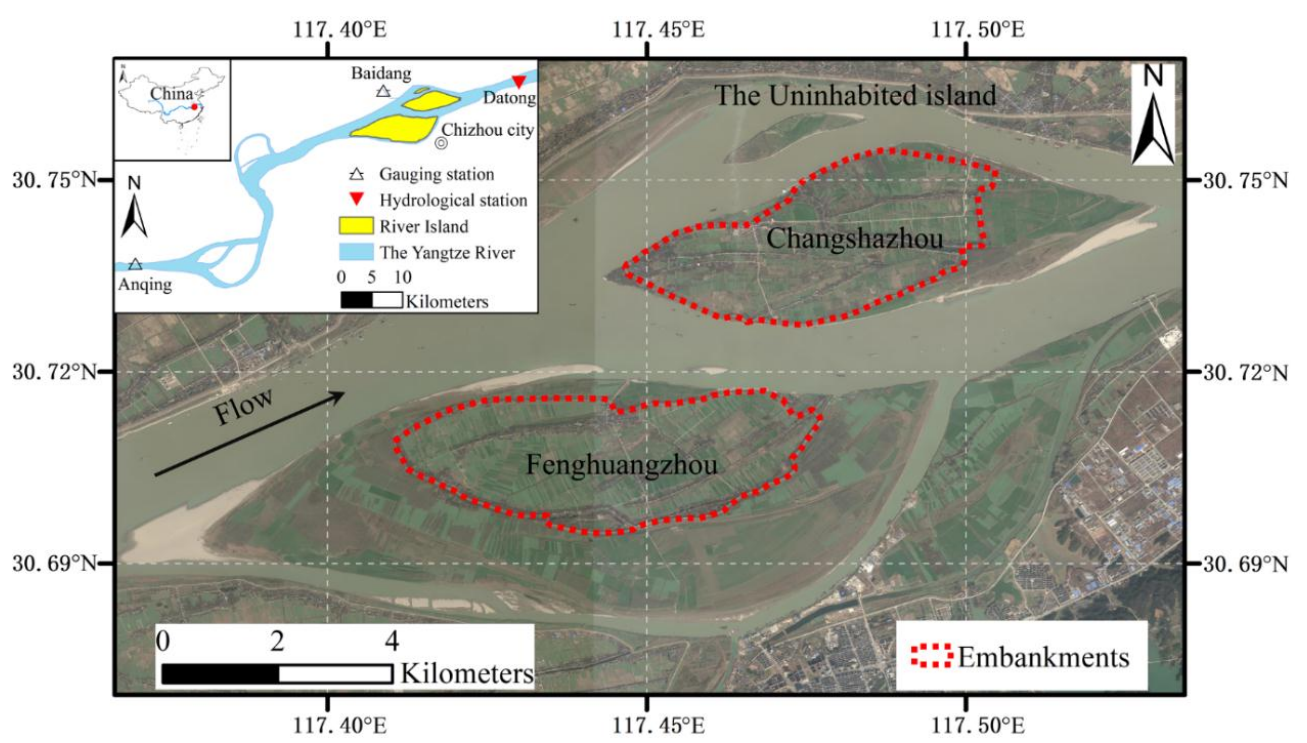

Figure 1. Map of the study site in the Yangtze River, showing the river islands Fenghuangzhou, Changshazhou and the uninhabited island by Google Earth image acquired on 21 January 2017.

At Anhui reach, the formation of the flood was mainly caused by channeling of the strong runoff (come from the upper and middle reaches of the Yangtze River), and the rainstorm flood (come from lakes, Chuanjiang River, and the Han River basin). The influence of the tributaries in the Anhui province is small, and the transit flood is the main source of flood. In Anhui province, the flood season of the Yangtze River is from May to October. The period from June to August is the high-water period. The highest water level in each hydrological station is mainly in this period; the dry season is from December to February. The lowest water level of each station over the years has mainly occurred 
in the dry season [39,40]. From the "2016 China Flood and Drought Disaster Bulletin" promulgated by the Ministry of Water Resources of the People's Republic of China, we know that, the rainfall in Anhui province during the flood season was $887 \mathrm{~mm}$, which was $27 \%$ more than the same period in the normal year. In the flood season of 2016, a major flood broke out in the Anhui reach of the Yangtze River, and the flood level was second only to 1954.

\subsection{Remotely Sensed Data}

In this study, Chinese GF-1 (GaoFen-1) WFV (wide field view) data were collected for our study owing to its high temporal frequency and high spatial resolution. GF-1 satellite was successfully launched by the Chinese Jiuquan satellite launch center at 26 April 2013. It is equipped with four multispectral scanners with 16-m resolution. Multispectral data obtained by GF-1 contain four bands with center wavelengths of $503 \mathrm{~nm}, 576 \mathrm{~nm}, 680 \mathrm{~nm}$, and $810 \mathrm{~nm}$, respectively. 16-m spatial resolution of GF-1 data can be a good way to capture the details of river island space, while their high frequency revisit time is only four days [41]. This paper collected the GF-1 data with a low cloud cover and better quality in the study area as the main data source, to accurately track the temporal changes of the river island. The Sentinel-2 data and Chinese GF-4 (GaoFen-4) VNIR (visible light near infrared) data acquired in October 2016, was collected for supplementary. In addition, GF-2 (GaoFen-2) PMS (pan and multi-attenuation sensor) data with 1-m spatial resolution was collected for the validation. The spatial resolution of Sentinel-2 data is $10 \mathrm{~m}$, and the GF-4 data is 16-m. GF-1, GF-2 and GF-4 data are downloaded from the Terrestrial Observing Satellite Data Service Platform [42] and the acquisition time is presented in Table 1. GF-1, GF-4 and Sentinel-2 daily images were mapped to a cylindrical equidistant projection at $16-\mathrm{m}$ spatial resolution $\left(\sim 0.00016^{\circ}\right)$.

Table 1. Experimental satellite data acquisition time.

\begin{tabular}{ccccccc}
\hline Data & \multicolumn{5}{c}{ Acquisition Time (Beijing Time) } \\
\hline & 2016.01 .26 & 2016.02 .03 & 2016.02 .16 & 2016.02 .20 & 2016.02 .28 & 2016.03 .11 \\
& 2016.03 .27 & 2016.03 .28 & 2016.04 .01 & 2016.04 .13 & 2016.04 .21 & 2016.04 .29 \\
GF-1 & 2016.04 .30 & 2016.05 .03 & 2016.05 .04 & 2016.05 .11 & 2016.05 .12 & 2016.05 .16 \\
& 2016.06 .05 & 2016.06 .13 & 2016.06 .14 & 2016.07 .08 & 2016.07 .24 & 2016.07 .25 \\
& 2016.07 .28 & 2016.07 .29 & 2016.08 .10 & 2016.08 .14 & 2016.08 .18 & 2016.08 .31 \\
& 2016.09 .12 & 2016.09 .20 & 2016.11 .04 & 2016.11 .11 & 2016.11 .28 & 2016.12 .02 \\
GF-4 & $2016.12 .15\{2\}$ & 2016.12 .28 & 2016.12 .31 & & $(11: 00: 00 \sim 11: 54: 28)$ & \\
Sentinel-2 & & \multicolumn{5}{c}{$2016.10 .09(09: 35: 12)$} \\
GF-2 & & $2016.10 .04(10: 59: 05)$ & \\
\hline
\end{tabular}

Note that $\{2\}$ represents two images in the same acquisition time (i.e., the same day).

\subsection{Hydrological Data}

In our analysis, water level data, monthly mean instantaneous runoff data, monthly mean suspended sediment concentration (SSC) data near the study area was used to explore the association between hydrological parameters and river islands. Daily water level, daily runoff and rainfall information about three station of the Datong hydrological station $\left(117.62^{\circ} \mathrm{E}, 30.76^{\circ} \mathrm{N}\right)$, Anqing gauging station $\left(117.05^{\circ} \mathrm{E}, 30.50^{\circ} \mathrm{N}\right)$ and Baidang gauging station $\left(117.42^{\circ} \mathrm{E}, 30.76^{\circ} \mathrm{N}\right)$ of the study area was collected from the Anhui hydrological telemetry information network [43]. The water level is based on the Wusong elevation system.

Datong hydrological station is located near the study area. It is a comprehensive hydrological station which is the nearest one to the estuary of the Yangtze River without being affected by tides. It is an important hydrological station as it is helpful for protecting water resources and controlling runoff from the Yangtze River to the sea. The water and sediment from upstream are abundant at Anhui reach. Annual average runoff (1950 2015) of Datong hydrological station is 8931 billion $\mathrm{m}^{3}$, and the average annual sediment discharge (1951 2015) is 3.68 billion tons. At Datong hydrological station, 
the maximum annual runoff is 13,600 billion $\mathrm{m}^{3}$ (1954), the maximum instantaneous flow value is $92,600 \mathrm{~m}^{3} / \mathrm{s}$ (1 August 1954) and the maximum flood-crest stage was $16.64 \mathrm{~m}$ (August 1954). In 2016, the annual runoff of Datong hydrological station was 10,450 billion $\mathrm{m}^{3}$, the maximum instantaneous flow was 70,700 $\mathrm{m}^{3}$ /s (11 July 2016) and the flood-crest stage was $15.66 \mathrm{~m}$ (8 July 2016). The hourly water level and flow information of the Datong hydrological station are collected. According to the acquisition time of remotely sensed data, the average of water level values collected at 11:00 and 12:00 is taken as the water level of the satellite transit instant (Figure 2). In addition, the monthly average of instantaneous runoff values and monthly mean SSC data were collected to study the relationship between the runoff, SSC, and the area of the islands.

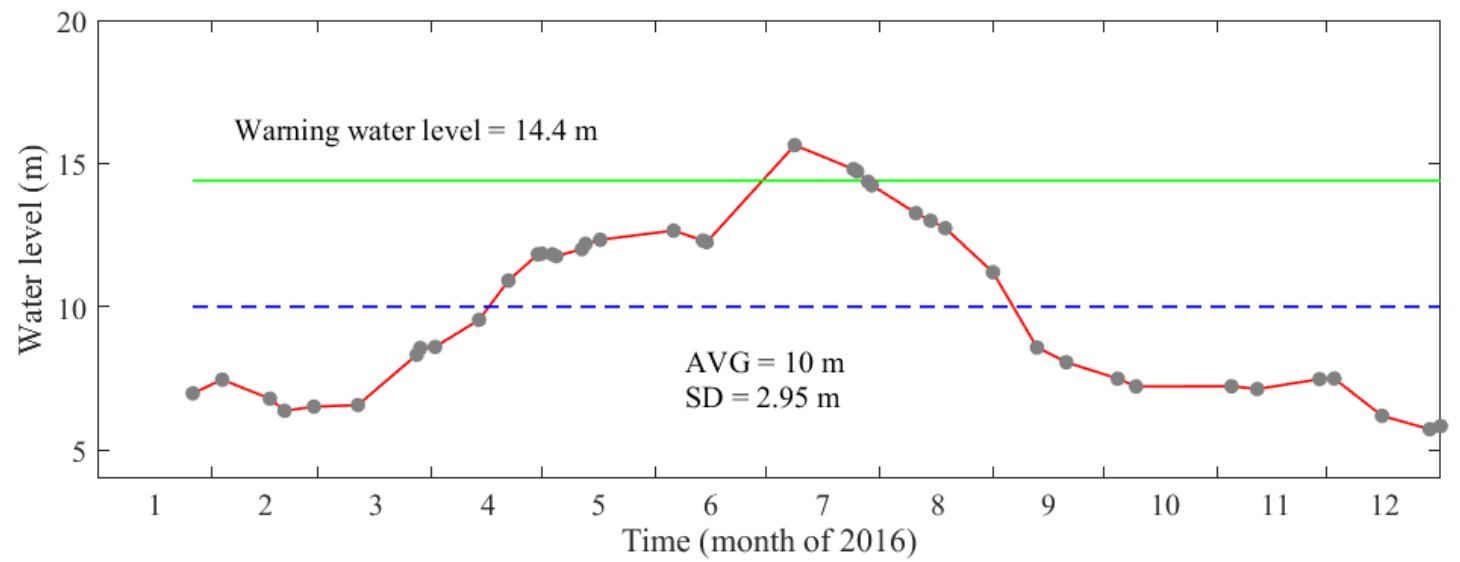

(a) The water level at remotely sensed data acquisition time.

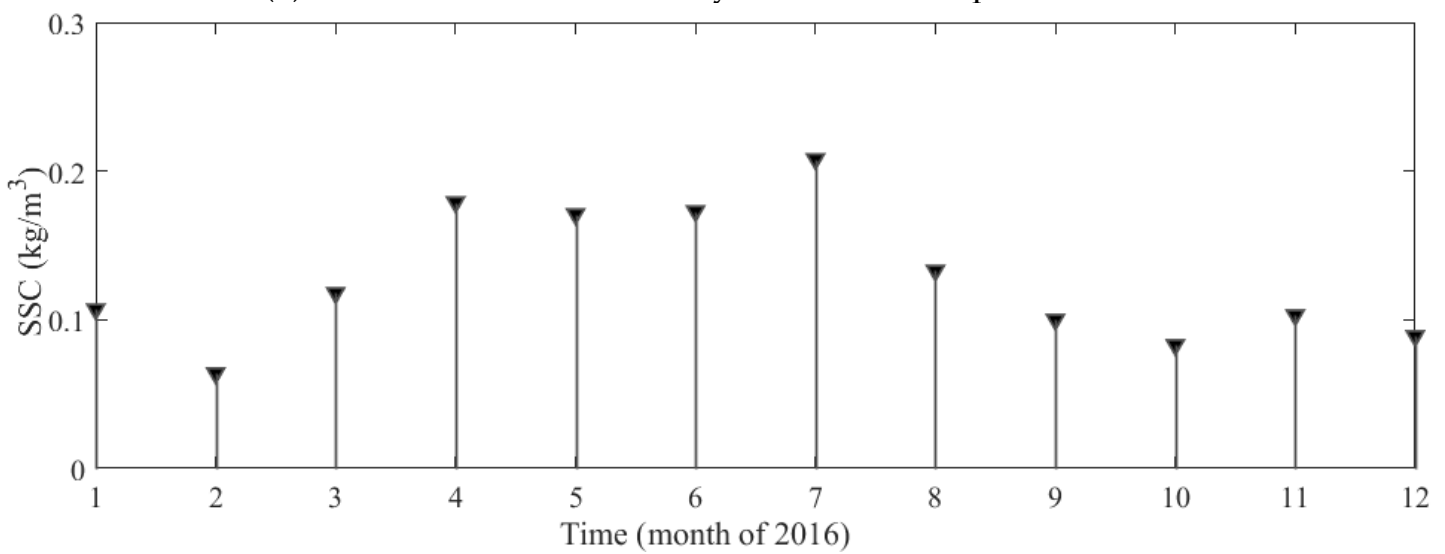

(b) The monthly mean suspend sediment concentration (SSC).

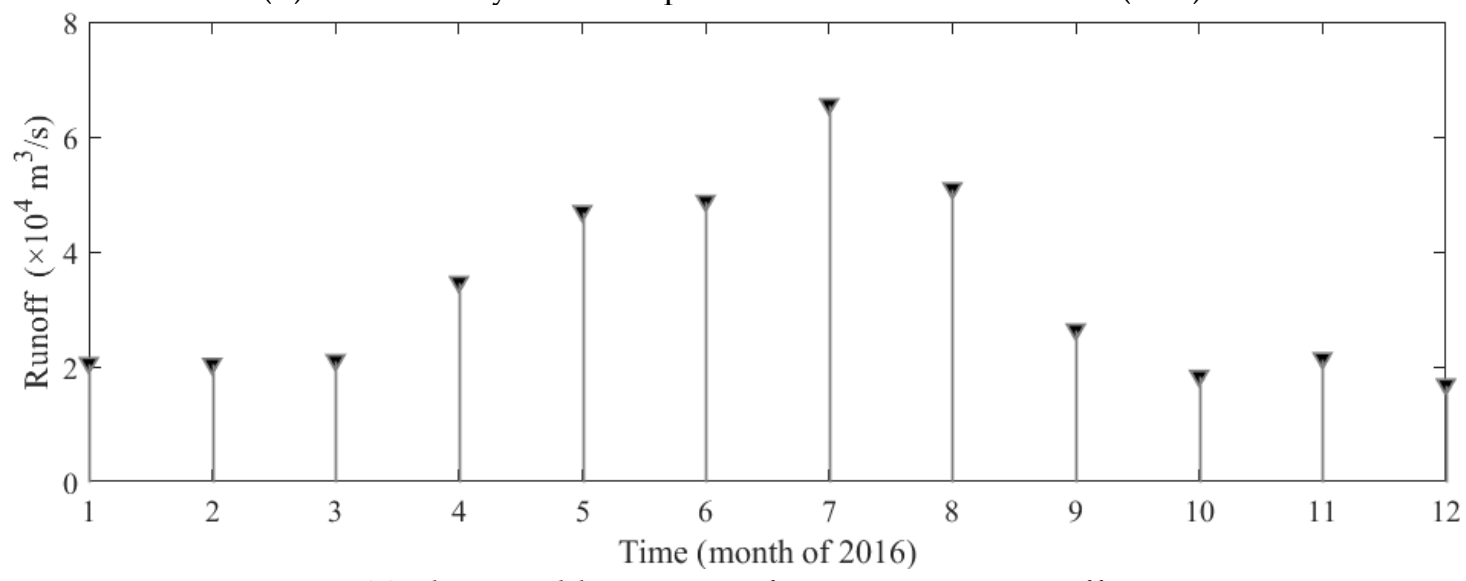

(c) The monthly average of instantaneous runoff.

Figure 2. Cont. 


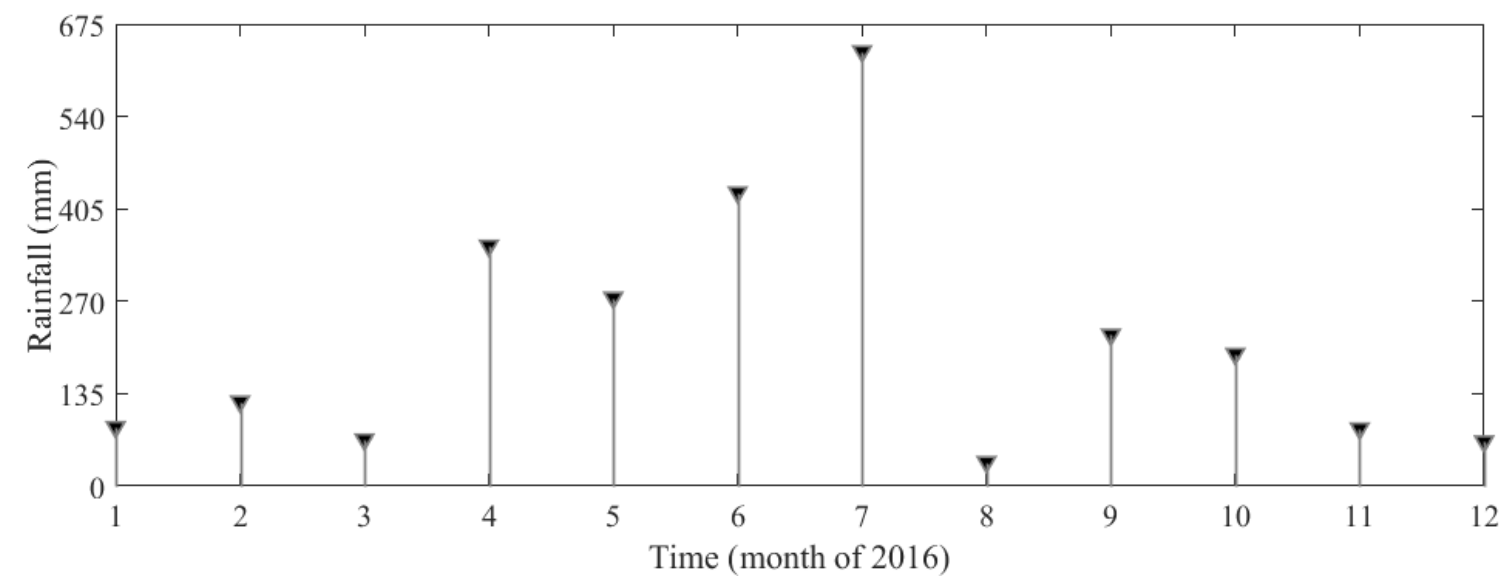

(d) The cumulative monthly rainfall.

Figure 2. Variation of the water level (a), SSC (b), runoff (c) and rainfall (d) at Datong hydrological station.

Anqing gauging station is located $4 \mathrm{~km}$ upstream of the study area. Baidang gauging station is located on the tributary of the study area, $2.5 \mathrm{~km}$ from the intersection of the tributary and the Yangtze River (Figure 1). Water level data from Anqing gauging station and Baidang gauging station were collected in the same way as Datong hydrological station.

\section{Methods}

Three mathematical models were constructed to estimate the relationship between the land area of the river island and measured water level. Three principal steps in this process are described in this section: Image processing for eliminating terrain effects or deformation, land-water classification for river islands mapping, defining the index for estimation of the risk in the river islands. High-resolution mapping results of GF-2 data are collected as the reference data to measure the accuracy of the results derived from GF-1 data. Human checking was then conducted to ensure the mapping quality.

\subsection{Image Processing}

We used ENVI5.2 software to carry out RPC (Rational polynomial coefficients) orthorectification without control points for GF-2, GF-1 and GF-4 data to eliminate terrain effects or deformation caused by camera orientation. The results of the orthorectification of the GF-2 data were obtained by implementing the GS transform (Gram-Schmidt Pansharping, GS), fusing the full-color band $(0.8 \mathrm{~m}$ resolution) and the multispectral band (4-m resolution) Information (1-m resolution) of multispectral images. GF-4 data and Sentinel-2 data were resampled to a 16-m resolution data based on the bilinear interpolation method. All the data are processed into Geotiff format and projected to WGS_1984_UTM_zone_50N coordinates.

\subsection{Water Extraction}

Clear water is highly absorptive in the infrared (IR) and slightly more reflective in the visible range [44]. Both vegetation and bare soil are more reflectively in the IR than in the visible. Therefore, the Normalized different water index (NDWI) proposed by McFeeters [45] is designed to: (1) maximize the reflectance of the water body in the green band; (2) minimize the reflectance of water body in the NIR band. To enhance water information and suppress non-water information, the NDWI for GF-1, GF-4, Sentinel-2 and GF-2 data is directly calculated as:

$$
\mathrm{NDWI}=\frac{\text { Green }-\mathrm{NIR}}{\text { Green }+ \text { NIR }}
$$


where Green and NIR are the raw Digital Numbers (DN) value of the Green and NIR bands. The resulting NDWI image values varied between -1 and 1 . Since the NDWI threshold can affect the accuracy of water extraction [46], a different, independently NDWI threshold was derived by raster color slice and histogram manually for each scene image. This method can capture the optimal threshold for each satellite image. The produced binary images were built with 0 means land and 1 means water.

\subsection{Estimation Risk in the River Island}

To evaluate the risk of river islands with the variation of water level, the risk index (RI) of river islands was constructed based on a ratio between the river flooding times and the total effective observation times,

$$
R I=\frac{\sum_{i=1}^{M} S N_{i}}{M}, S N_{i}=\left\{\begin{array}{c}
1, \text { Water } \\
0, \text { Land }
\end{array}\right.
$$

where $M$ is the total effective observation time, $S N$ is value of pixels with 1 indicates flood area, 0 indicates unflooded area. The resulting RI values varied between 0 and 1 . The closer the RI value is to 0 , the safer it is; the closer the RI value is to 1 , the more dangerous it is.

\subsection{Evaluation of Mapping Accuracy}

In this study, Overall Accuracy (Equation (3)), User Accuracy (Equation (4)), Producer Accuracy (Equation (5)) and Kappa Coefficient (Equation (6)) were used for the accuracy assessment of mapping from the GF-1 data. The series of accuracy metrics can be derived from a confusion matrix which is the most frequently used method in accuracy assessment [47].

$$
\begin{gathered}
\text { Overall Accuracy }=100 \times \sum_{i=1}^{r} \frac{N_{i i}}{i} \\
\text { User Accuracy }=\frac{N_{i i}}{N_{i+}} \\
\text { Producer Accuracy }=\frac{N_{i i}}{N_{+i}} \\
\text { Kappa Coefficient }=\frac{N \times \sum_{i=1}^{r} N_{i i}-\sum_{i=1}^{r} N_{i+} \times N_{+i}}{N^{2}-\sum_{i=1}^{r} N_{i+} \times N_{+i}}
\end{gathered}
$$

where $N_{i i}$ is the number of correctly samples of class $i . r$ is the number of classes; $N$ is the number of training samples; $N_{+i}$ is the number of training samples of class $i . N_{i+}$ is the number of classified samples of class $i$.

\section{Results and Discussion}

\subsection{Accuracy Evaluation}

To evaluate the mapping results from GF-1 data (16-m), GF-2 data with a higher spatial resolution (1-m) was used. The acquisition time of the data used for evaluation are very close, while GF-2 data is 11 August 2016 and GF-1 data is August 10, 2016. The confusion matrix between the mapping results of GF-2 data and the GF-1 data has been shown in Table 2, which is used for accurate evaluation. Among the 320,672 pixels of the study area, 116,592 pixels were successfully identified as river island pixels, and 187,217 pixels were successfully identified as water body pixels, with a total accuracy of $94.74 \%$ and a Kappa coefficient of $88.95 \%$. Therefore, the accuracy of adopting the NDWI threshold method to mapping river island is higher, which can meet our needs for river mapping. 
Table 2. Confusion matrix obtained by NDWI methods.

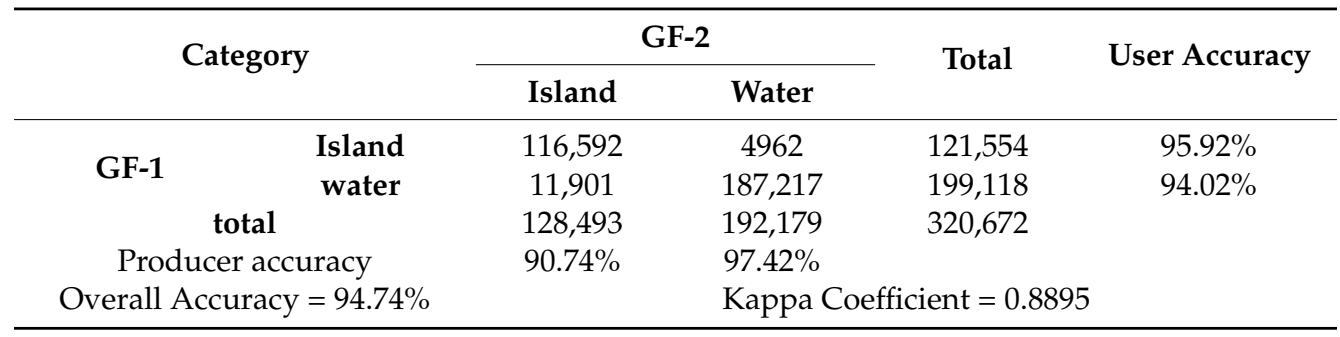

\subsection{Temporal Change of River Island Area and Water Level}

Figure 3 shows the temporal change of the river islands in the study area. The area of the river island exhibited obvious seasonal variations and certain short-term fluctuations. Similarly, the water level also exhibited a significant seasonal variation and certain short-term fluctuations. The difference between the maximum and minimum land areas of the river island is defined as the intra-annual fluctuation of the river island land. We found that the annual area fluctuation of Fenghuangzhou, Changshazhou, and the uninhabited island is $21.04 \mathrm{~km}^{2}, 4.4 \mathrm{~km}^{2}, 0.83 \mathrm{~km}^{2}$ respectively, during January 2016 to December 2016. The water level in the Datong hydrological station was fluctuated between $5.72 \mathrm{~m}$ and $15.63 \mathrm{~m}$. The water level average of Datong hydrological station, Baidang gauging station and Anqing gauging station are $10.14 \mathrm{~m}, 11.69 \mathrm{~m}$, and $11.79 \mathrm{~m}$ respectively, and the standard deviation is $2.96 \mathrm{~m}, 1.90 \mathrm{~m}$, and $3.28 \mathrm{~m}$, respectively.

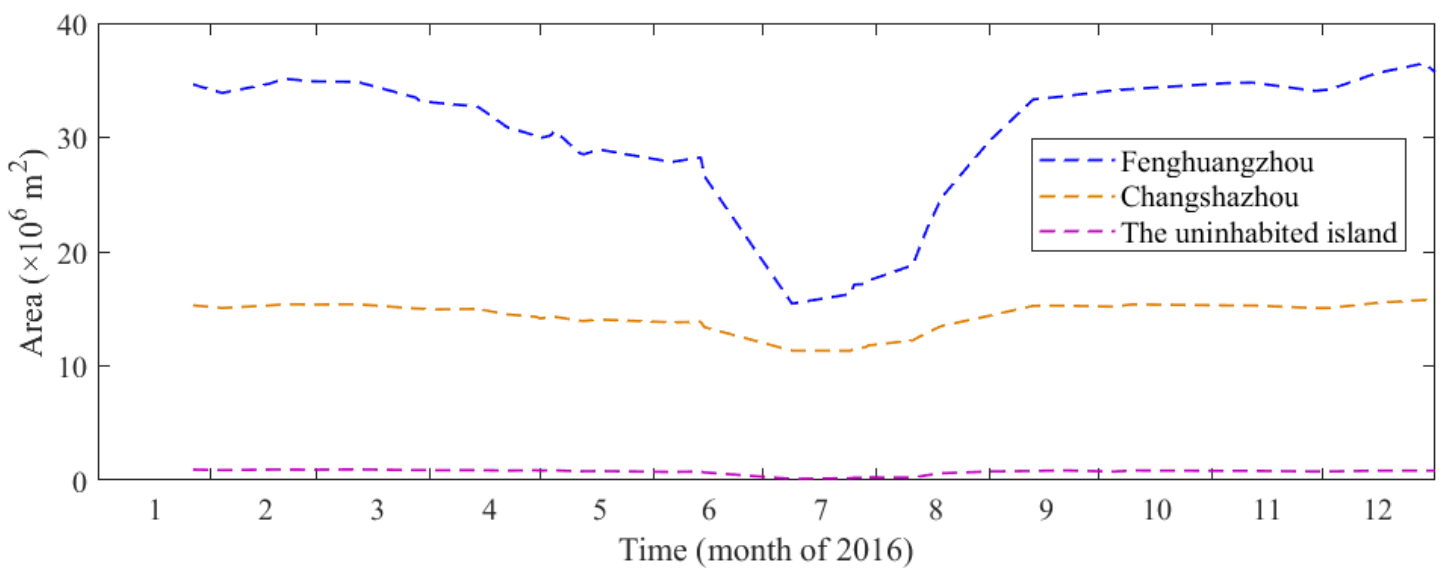

Figure 3. River islands change with the water level.

The land areas of the river islands are highly affected by the dry season and the flood season, showing a significant intra-annual variation pattern of first shrinking and then expanding (Figure 2). The change area of the river islands at the beginning and end of 2016 is defined as the net change during this year. The change of the water level at the beginning and end of 2016 is defined as the net change of water level during this year. The calculation shows that the net change in land of three islands Fenghuangzhou, Changshazhou and the uninhabited island studied are $-1.06 \mathrm{~km}^{2},-0.34 \mathrm{~km}^{2}$, $+0.09 \mathrm{~km}^{2}$, respectively. The net change in the upstream water level (Anqing gauging station) is $+1.45 \mathrm{~m}$ and the net change in the nearby water level (Datong hydrological station) is $+1.14 \mathrm{~m}$. The net change of the tributary water level (Baidang gauging station) is $-0.74 \mathrm{~m}$. The net change around the river island is much smaller than its fluctuation during the year, and the conclusion is similar for the water level. The net change of area of river islands are mainly caused by the net change of water level. We estimated the relationship between land area of river islands and water level and found a strong negative correlation $\left(R^{2}>0.8, P<0.001\right)$. The calculations were conducted for Fenghuangzhou, Changshazhou and one uninhabited island, and similar conclusions were obtained. 
As shown in Figure 2a, from 30 April to 31 August 2016, water levels of the three hydrological stations are observed during the high water level period throughout the year. This period is the high water level period of the Yangtze River in the flood season, and the land area of the river island is relatively small. The land area of the river island decreased with the increase of water level and increased with the decrease of water level. In addition to the obvious seasonal patterns, we found that the land area of the river island showed certain short-term variations, such as 3 February, 5 June, and 15 December. The water level at the corresponding moment also shows a certain variability. This shows that the water level changes can affect the change of the land area of the river island, from the season scale to a shorter time scale. Together with the measured rainfall information of the hydrological station and the forecast of the meteorological department, the middle and lower reaches of the Yangtze River continued to rain, and heavy rain occurred in some areas, from 16 June to 6 July. The minimum land area of total three river islands is $26.90 \mathrm{~km}^{2}$, on 8 July 2016 (Figure $4 \mathrm{~b}$ ). At that time, water levels in three hydrological stations were all the highest water level (17.66 m in Anqing gauging station, $15.23 \mathrm{~m}$ in Baidang gauging station and $15.63 \mathrm{~m}$ in Datong hydrological station), and above the warning water level. The maximum land area of three river islands appeared in the dry season on 28 December 2016, which was $53.09 \mathrm{~km}^{2}$ (Figure 4a). At the same time, Anqing gauging station and Datong hydrological station were the lowest water levels, $6.86 \mathrm{~m}$, and $5.72 \mathrm{~m}$, respectively.

The embankment is the guarantee for the life and property safety, social and economic development of the residents of the river island. In the flood season in 2016, both Fenghuang embankment and Changsha embankment were not broken, and land areas surrounded by the embankment were about $11 \mathrm{~km}^{2}, 10 \mathrm{~km}^{2}$, respectively. On $8 \mathrm{July}$, the land area of Changshazhou and Fenghuangzhou was about $11.33 \mathrm{~km}^{2}$ and $15.45 \mathrm{~km}^{2}$, respectively. At the same time, the uninhabited island without embankment protection was largely submerged, and only about $0.12 \mathrm{~km}^{2}$ were not submerged. Moreover, we continuously monitor the area of the river and can capture short-term changes. During 29 April and 4 May, the water level first increased from $11.83 \mathrm{~m}$ to $11.85 \mathrm{~m}$, and then dropped back to $11.75 \mathrm{~m}$, the total area of river islands also changed synchronously.

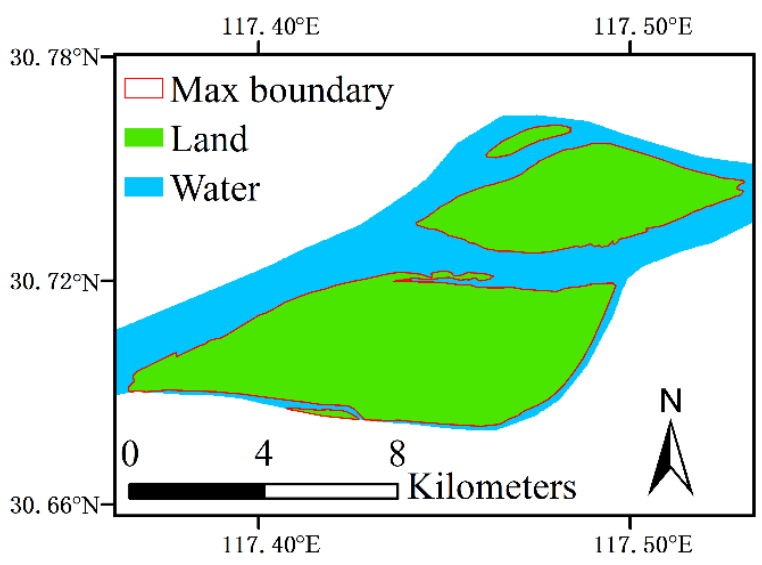

(a)

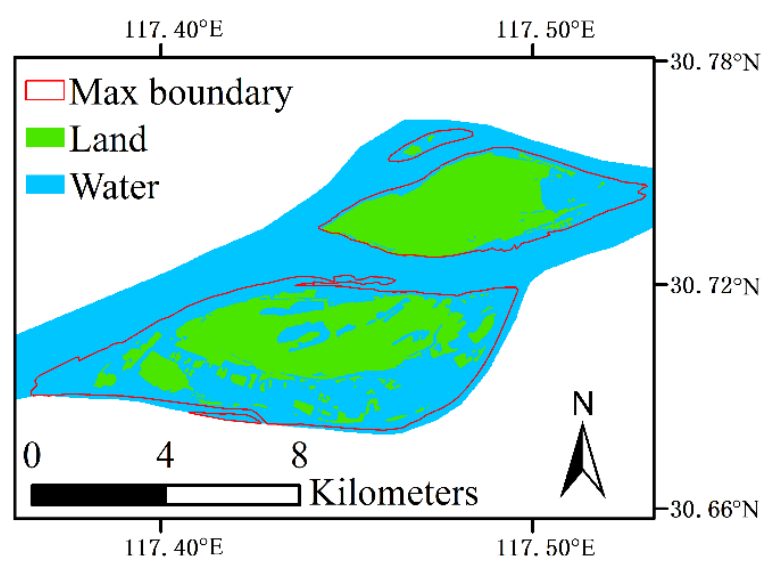

(b)

Figure 4. The maximum (a) and minimum (b) area of the river island.

\subsection{Relationship between River Island Area and Water Level}

To explore the relationship between land area change and the water level change, we collected water level data near the river island. Three models of primary function, quadratic function, and cubic function are used to characterize the relationship between the land area of the river island and the water level at the corresponding imaging time (Figure 5).

The calculations demonstrate that all these three models indicate significant correlations between the land area of river islands and the measured water level. This conclusion is similar to the water level data of the three water stations: the $R^{2}$ of the fitted model is higher than 0.55 , and the $P$ values are 
less than 0.001. However, we can discover some differences among the three models. The correlation between the water level measured by Datong hydrological station and the area of Fenghuangzhou, Changshazhou is higher than the uninhabited island. Since the unmanned island is too small, it is greatly affected by the error caused by the satellite image resolution. The correlation between the water level measured by Datong hydrological station and the area of river islands is higher than that the other two hydrological station, due to the location of the hydrological station and its distance from the study area. Anqing gauging station is located $4 \mathrm{~km}$ upstream of the study area, while Datong is the nearby hydrological station. Baidang gauging station is located on the tributary of the study area, $2.5 \mathrm{~km}$ from the intersection of the tributary and the Yangtze River. Baidanghu sluice is a drainage station, water level of Baidang gauging station is higher than the actual water level from the Yangtze River, and it cannot accurately represent the water level information of the Yangtze River near the river island.

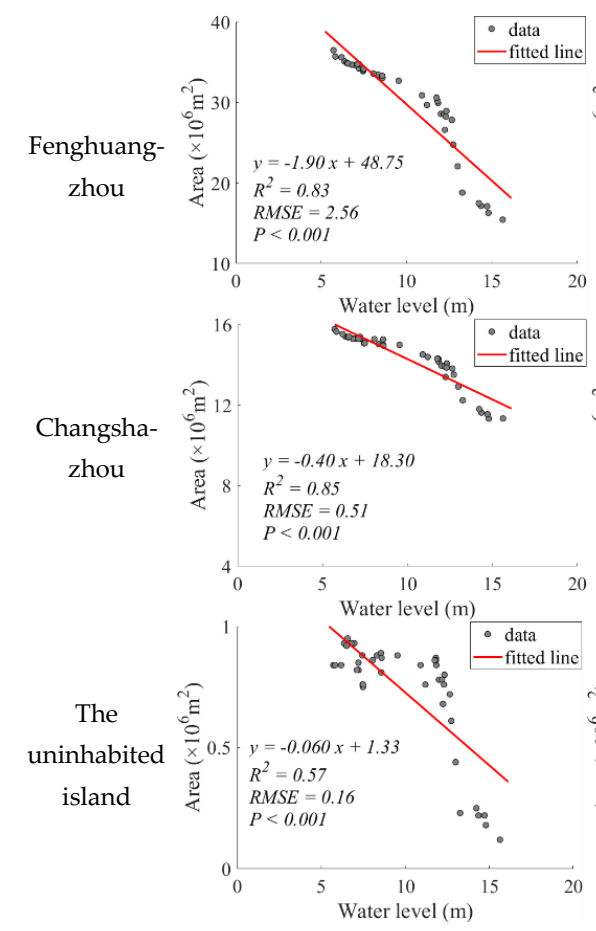

(a) primary function

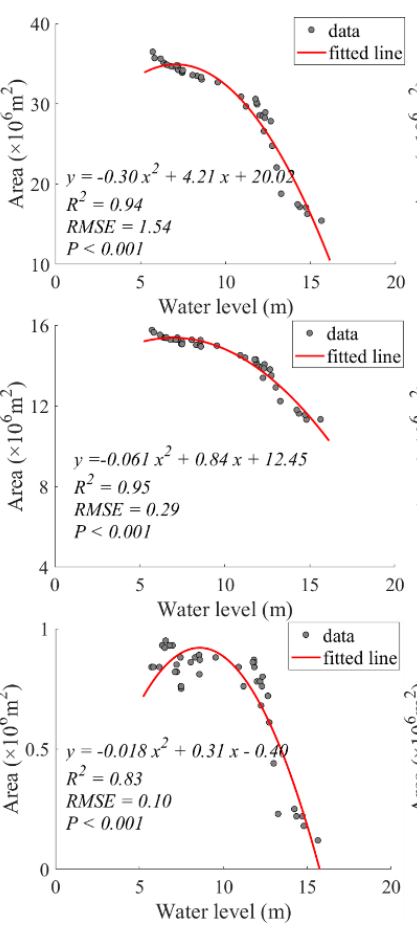

(b) quadratic function

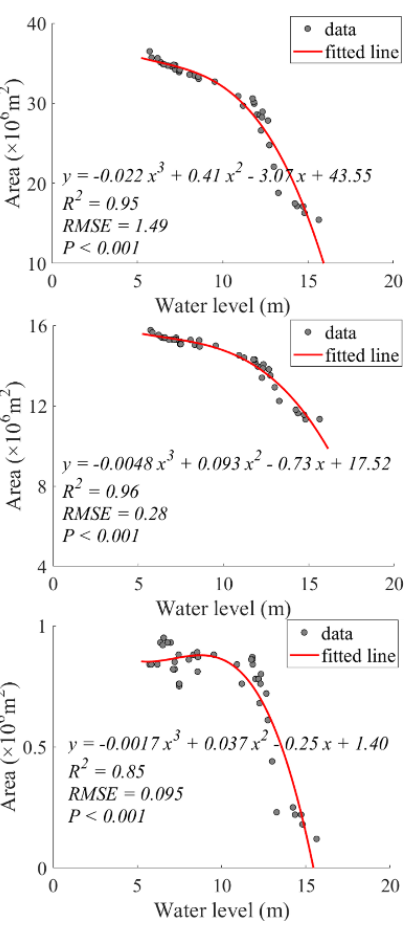

(c) cubic function

Figure 5. Relationships between the area of river islands and the water level of Datong hydrological stations.

Additionally, these three fitted models showed some differences in the fitting. Among them, the cubic function performs the best in the fitting $\left(R^{2}>0.85, P<0.001\right)$. This also reflects the complex nonlinear relationship between the land area of the river island and the water level in the Yangtze River, which is mainly controlled by the topography of the river island tidal flat.

\subsection{Relationship between River Island Area and SSC}

As shown in Table 3, compared with the multi-year average water and sand characterization values between 2007 2016, the annual runoff and the annual sediment discharge of Datong hydrological station in 2016 are $20 \%$ and 17\% larger, respectively. Compared with annual water and sand characterization values in 2015, the annual runoff and the annual sediment discharge of Datong hydrological station in 2016 are $14 \%$ and 31\% higher, respectively. Moreover, annual runoff and annual sediment discharge in Datong hydrological station in 2016 were mainly concentrated in May-October, with the annual runoff and annual sediment discharge accounting for $66 \%$ and $72 \%$ of the year, respectively. 
Table 3. Interannual comparison of water and sediment characteristic of Datong hydrological station.

\begin{tabular}{cccc}
\hline Characteristics & $\begin{array}{c}\text { Annual Runoff } \\
\left(\mathbf{1 0}^{\mathbf{8}} \mathbf{~}^{\mathbf{3}} \mathbf{)}\right.\end{array}$ & $\begin{array}{c}\text { Annual Sediment } \\
\left.\text { Discharge } \mathbf{( 1 0 ^ { 8 }} \mathbf{T}\right)\end{array}$ & $\begin{array}{c}\text { Annual Average Sediment } \\
\left.\text { Concentration } \mathbf{( k g} / \mathbf{m}^{\mathbf{3}}\right)\end{array}$ \\
\hline Multi-year average & 8712 & 1.3 & 0.414 \\
2015 & $(2007-2016)$ & $(2007-2016)$ & $(1951-2015)$ \\
2016 & 9139 & 1.16 & 0.127 \\
\hline
\end{tabular}

To explore the association between the area of river islands and SSC, the primary function model was used to describe the relationship between monthly mean SSC of Datong hydrological station and monthly average area of river islands (Figure 6). The calculations show that there is a significant correlation between the area of river islands and SSC $(P<0.05)$.

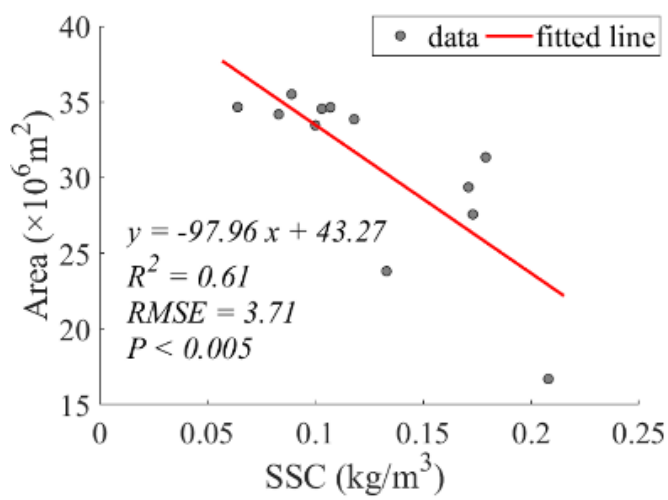

(a) Fenghuangzhou

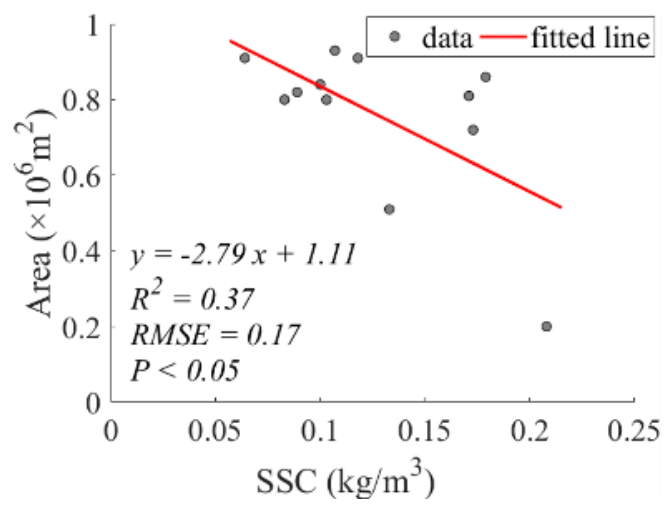

(c) The uninhabited island

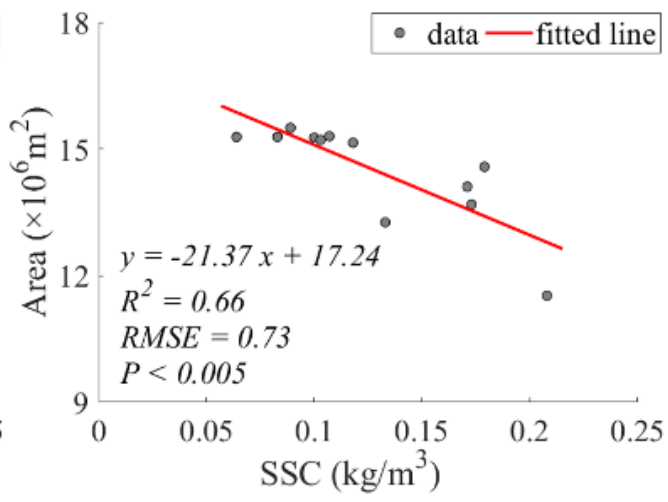

(b) Changshazhou.

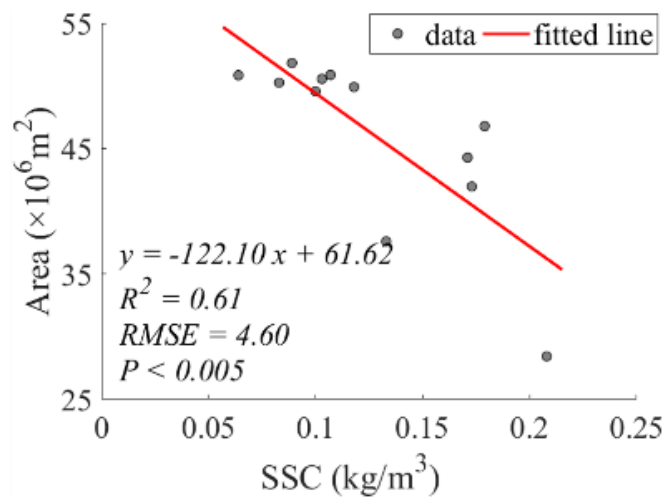

(d) all the islands.

Figure 6. Relationships between monthly area of river islands and the monthly mean SSC of Datong hydrological station.

Also, from the long-term monitoring results, the annual sediment discharge of Datong hydrological station exhibited a general decreasing trend (Figure 7), for three reasons: 1. Since 1989, China has implemented soil and water conservation projects in the upper reaches of the Yangtze River to restore vegetation; 2 . The scouring and silting changes of the Yangtze River, lakes and tributaries have a certain adjustment effect on the sediment discharge of Datong hydrological station; 3 . Due to the large number of water conservancy projects constructed in the upper reaches of the Yangtze River (such as the Gezhouba Water Conservancy Project, the Three Gorges Dam), a large amount of sediment is deposited in the reservoir. However, under the influence of flood discharge in the flood season in 2016, the flow is turbulent, and the sediment from the middle and upper reaches of the Yangtze River and its tributaries significantly increased compared to 2015. With the changes of runoff and sediment volume in this period, river islands also exhibited some variations. 


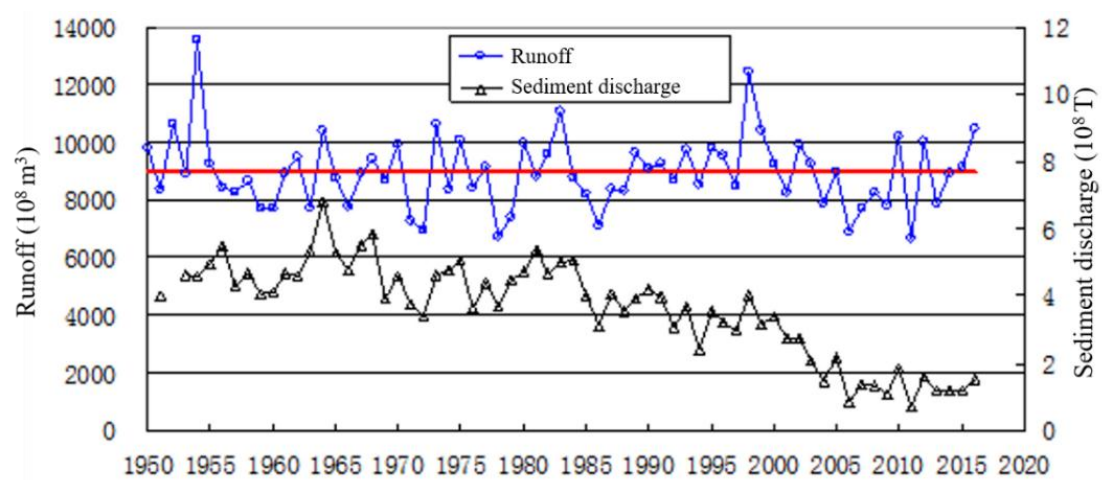

Figure 7. Changes in runoff and sediment discharge in Datong hydrographic station over the past decades.

\subsection{Relationship between River Island, Runoff and Rainfall}

Apart from water level and SSC, some other potential factors (such as runoff, rainfall) can also contribute to the temporal change of river islands. To quantify the association between the area of river islands, runoff and rainfall, the primary function model was used to describe the relationship between monthly mean instantaneous runoff (Figure 8), monthly cumulative rainfall (Figure 9) and monthly average area of river islands. The calculation shows that the runoff and the river island area have strong correlation for each one (Fenghuangzhou: $R^{2}=0.91, P<0.001$; Changshazhou: $R^{2}=0.92$, $P<0.001$; the uninhabited island: $\left.R^{2}=0.68, P<0.001\right)$ and the total $\left(R^{2}=0.91, P<0.001\right)$. Moreover, there is a significant correlation between the area of river islands and the cumulative monthly rainfall for each one (Fenghuangzhou: $R^{2}=0.49, P<0.05$; Changshazhou: $R^{2}=0.53, P<0.01$; the uninhabited island: $\left.R^{2}=0.37, P<0.05\right)$ and the total $\left(R^{2}=0.49, P<0.05\right)$. Additionally, a significant positive relationship was found between runoff and rainfall $\left(R^{2}>0.52, P<0.01\right)$.

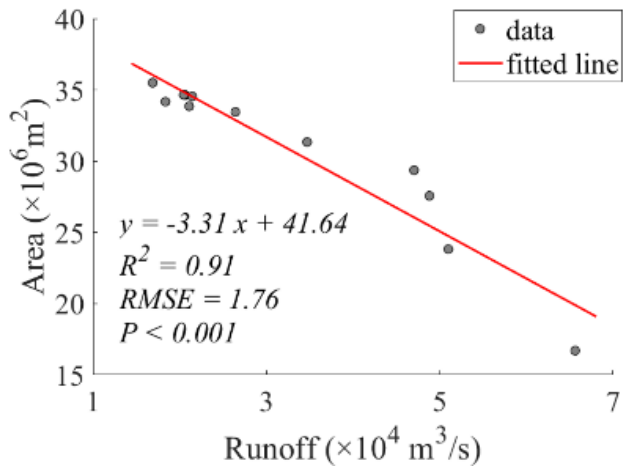

(a) Fenghuangzhou

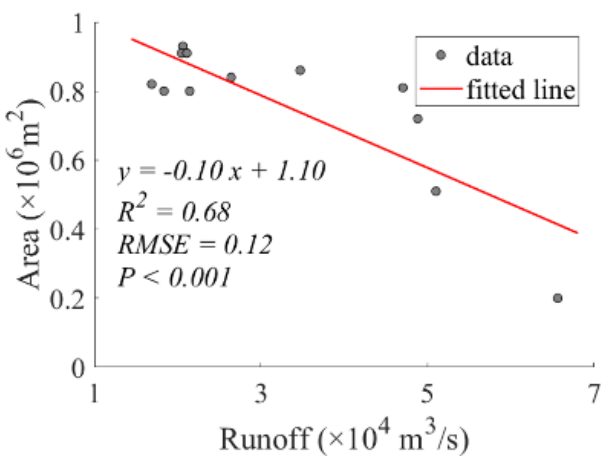

(c) The uninhabited island

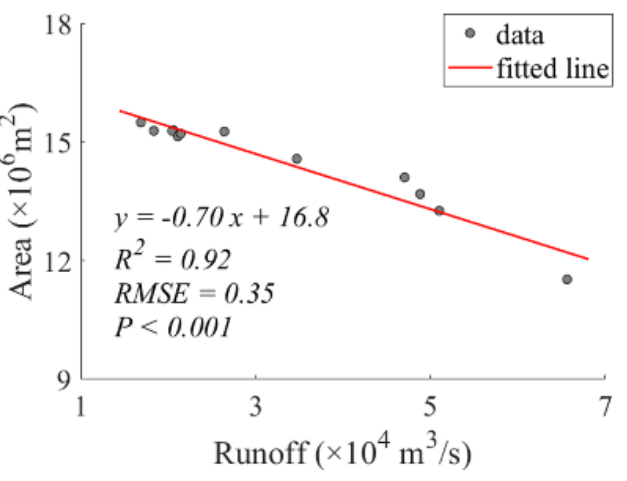

(b) Changshazhou.

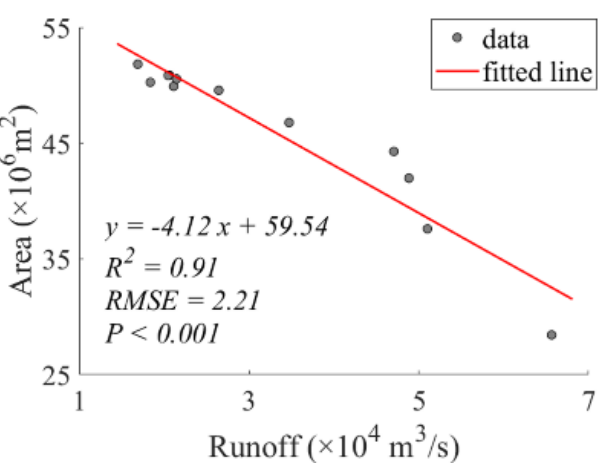

(d) all the islands.

Figure 8. Relationships between monthly area of river islands and the monthly mean instantaneous runoff of Datong hydrological station. 


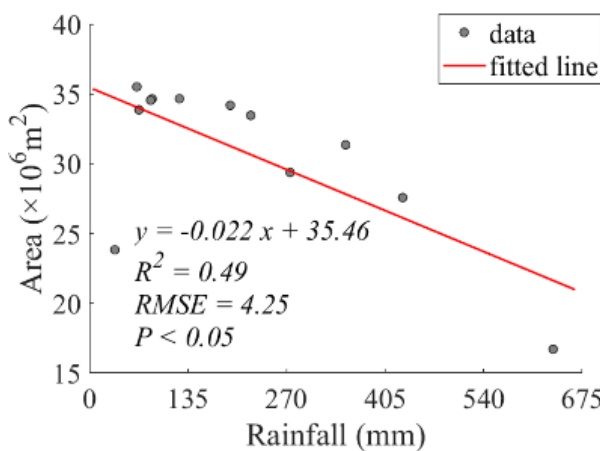

(a) Fenghuangzhou

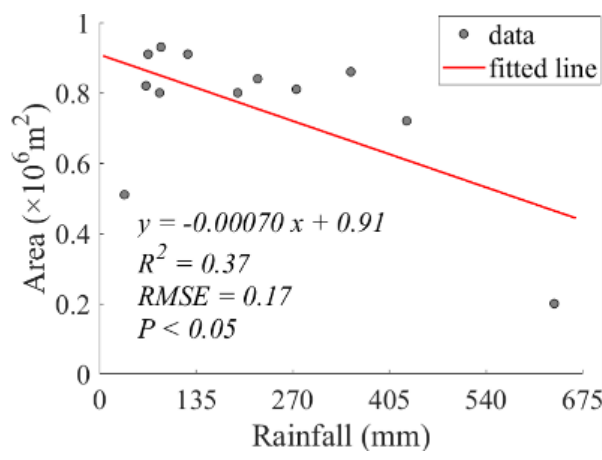

(c) The uninhabited island

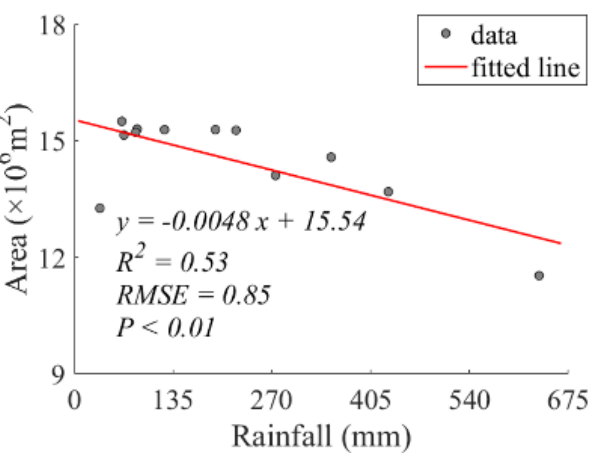

(b) Changshazhou.

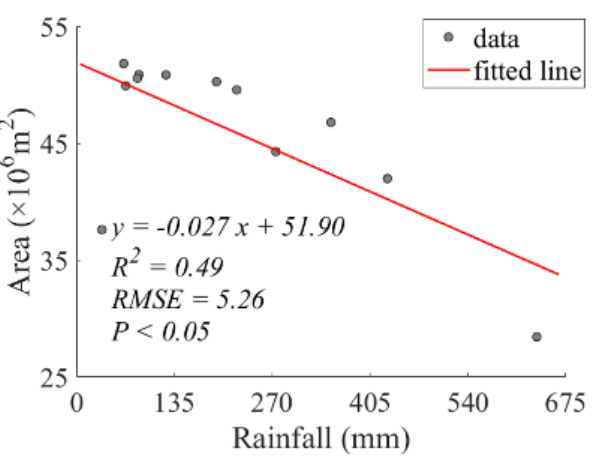

(d) all the islands.

Figure 9. Relationships between monthly area of river islands and the cumulative monthly rainfall of Datong hydrological station.

\subsection{Flooding Risk of River Islands}

We used the frequency of river islands' inundation to reflect the risk of flooding of those river islands. From Figure 10, we can see that the spatial distribution of the risk of submergence in the study area. Red represents the highest value of 1 and green represents the lowest value of 0 . Please note that a larger value indicates a higher flooding risk. According to the RIs, we define areas with a RIs less than 0.1 as safe areas, and areas with a RI greater than 0.5 as dangerous areas. Calculations show that the studied river island owns $29.37 \mathrm{~km}^{2}$ safe areas, accounting for $52.39 \%$ of the total land area of river islands; $26.69 \mathrm{~km}^{2}$ are vulnerable to floods, of which $8.45 \mathrm{~km}^{2}$ are dangerous areas, accounting for $15.07 \%$ of the total land area of river islands. These areas are mainly located on the banks of river islands and on the banks of the rivers. Moreover, during the past decades, the runoff and SSC exhibited a dramatic decrease after the impoundment of Three Gorges Dam in June 2003 [48]. To better predict the risk of river islands, data on runoff and sediment at a long-term scale was required. 


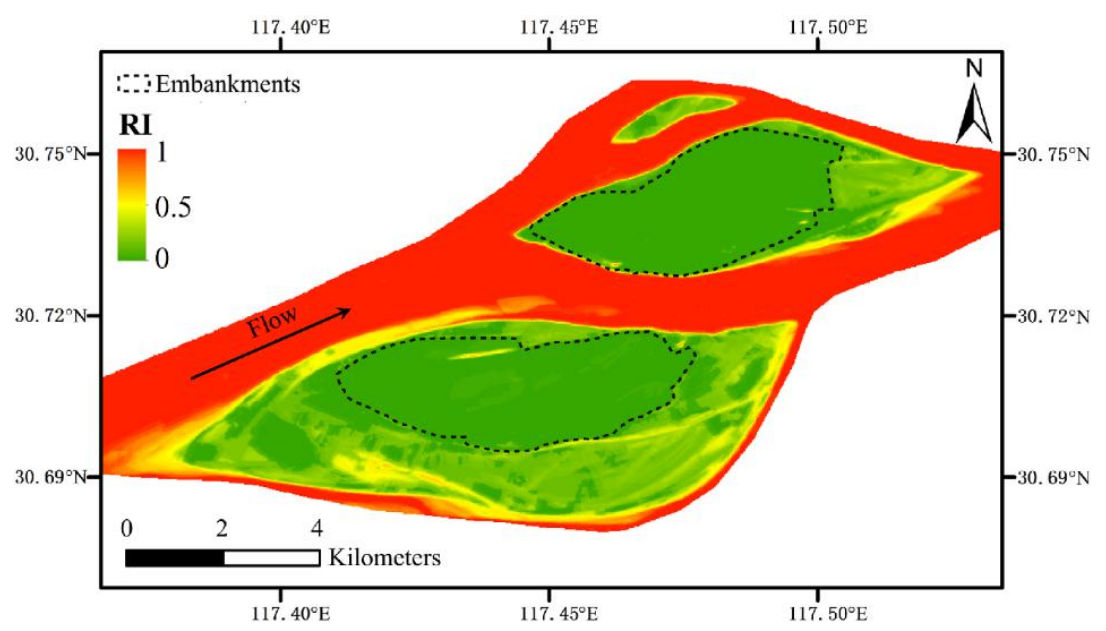

(a) Risk Index (RI) mapping of river islands.

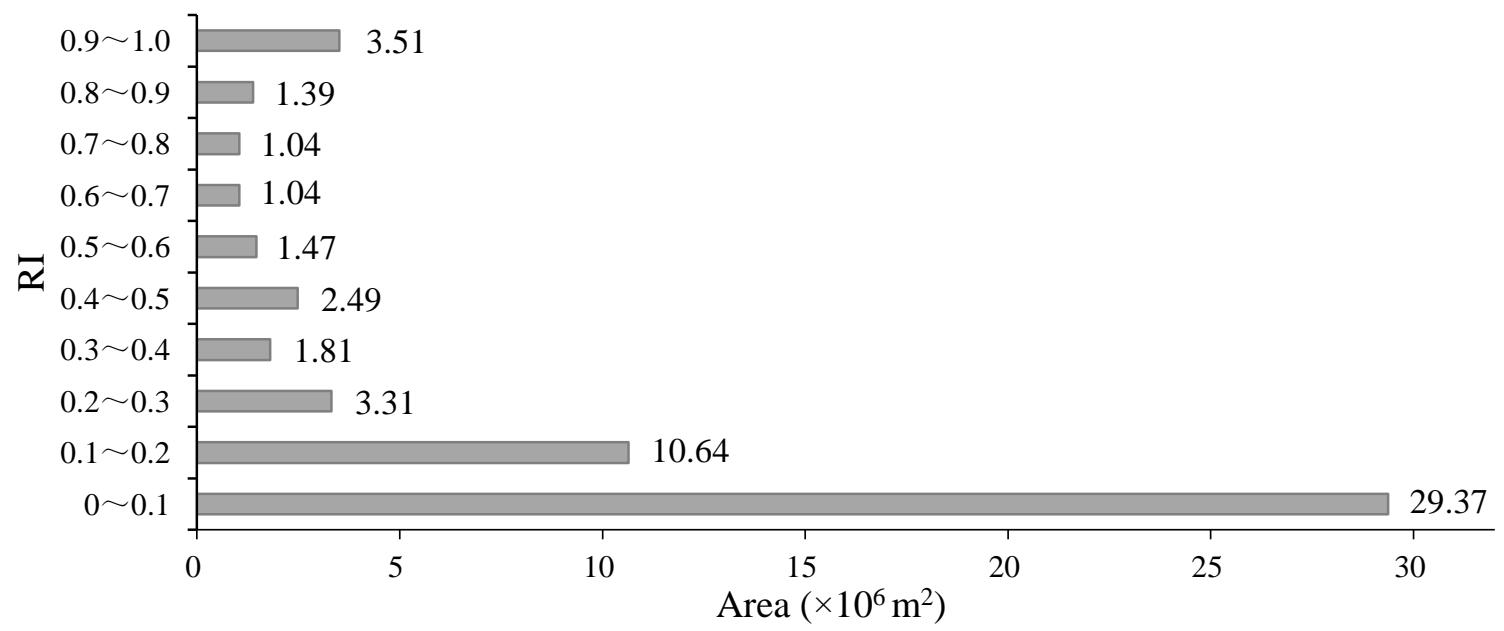

(b) Interval statistical results of RI.

Figure 10. The river island Inundation Risk Index.

\section{Conclusions}

Our results confirmed the availability of GF-1 data in temporal monitoring of river islands. This paper takes three river islands at the Yangtze River as an example, using Chinese GF-1 satellite data as the main data source, together with methods of water index and threshold segmentation, to monitor the temporal change of river islands. GF-2 data with higher spatial resolution were used for validation with the accuracy of $94.74 \%$. Using the proposed method in this paper, seasonal variations and certain short-term fluctuations of land areas of three typical river islands in the Yangtze River can be observed. Based on the hydrological station data, we explored the correlation between the land area of the river island and the water level of the Yangtze River. The cubic function can better describe the relationship between land area and water level $\left(R^{2}>0.8, P<0.001\right)$. The temporal variation of the river island was mainly controlled by the variation of the water level during the year. Moreover, we can capture the abrupt change in river islands induced by flooding-driven water level variations.

In addition, we generated a spatial distribution map of river islands inundation risk. We found that areas with high risk are mainly located in the boundaries of the river island. This provides a basis for flood forecasting and post-disaster reconstruction and can be applied to other similar river islands.

Author Contributions: J.S. and N.X. designed the broad research strategy for the work, collected the data, executed the analysis, and finished the manuscript. L.D. and J.L. contributed to the result analysis. H.Q. and M.H. revised the manuscript. 
Funding: This research was partially supported by the Youth Science and Technology Innovation Fund Project (No. KY201703), which provided by Anhui Province Key Laboratory of Water Conservancy and Water Resources.

Acknowledgments: The authors gratefully acknowledge the anonymous reviewers and editors for their careful reviews and suggestions, which significantly contributed to the manuscript improvement.

Conflicts of Interest: The authors declare no conflict of interest.

\section{References}

1. Gao, C.; Chen, S.; Yu, J. River islands' change and impacting in the lower reaches of the Yangtze River based on remote sensing. Quat. Int. 2013, 304, 13-21. [CrossRef]

2. Bai, J.; Li, Y.B. Analysis of riverbed evolution and trend prediction for Jiangxinzhou waterway of the lower Yangtze River. J. Waterw. Harb. 2009, 30, 347-351.

3. Carling, P.; Jansen, J.; Meshkova, L. Multichannel rivers: Their definition and classification. Earth Surf. Proc. Land. 2014, 39, 26-37. [CrossRef]

4. Huang, H.Q.; Nanson, G.C. Why some alluvial rivers develop an anabranching pattern. Water Resour. Res. 2007, 43, W07441. [CrossRef]

5. Gilvear, D.; Willby, N. Channel dynamics and geomorphic variability as controls on gravel bar vegetation: River Tummel, Scotland. River Res. Appl. 2006, 22, 457-474. [CrossRef]

6. Mani, P.; Kumar, R.; Chatterjee, C. Erosion study of a part of Majuli River-Island using remote sensing data. J. Indian Soc. Remote Sens. 2003, 31, 12-18. [CrossRef]

7. Joeckel, R.M.; Henebry, G.M. Channel and island change in the lower Platte River, Eastern Nebraska, USA: 1855-2005. Geomorphology 2008, 102, 407-418. [CrossRef]

8. Liu, X.; Huang, H.; Deng, C. A theoretical investigation of the hydrodynamic conditions for equilibrium island morphology in an abranching rivers. Adv. Water Sci. 2014, 25, 477-483.

9. Chuurman, F.; Kleinhans, M.G. Bar dynamics and bifurcation evolution in a modelled braided sand-bed river. Earth Surf. Proc. Land. 2015, 40, 1318-1333. [CrossRef]

10. Wang, Z.; Huang, W.; Li, Y. Sediment budget of the Yangtze River. J. Sediment Res. 2007, 2, 1-10. [CrossRef]

11. Wella-Hewage, C.S.; Hewa, G.A.; Pezzaniti, D. Can water sensitive urban design systems help to preserve natural channel-forming flow regimes in an urbanised catchment? Water Sci. Technol. 2016, 73, 78-87. [CrossRef] [PubMed]

12. Park, E.; Latrubesse, E.M. Modeling suspended sediment distribution patterns of the Amazon River using MODIS data. Remote Sens. Environ. 2014, 147, 232-242. [CrossRef]

13. Grove, J.R.; Croke, J.; Thompson, C. Quantifying different riverbank erosion processes during an extreme flood event. Earth Surf. Proc. Land. 2013, 38, 1393-1406. [CrossRef]

14. Zhang, L.J.; Qian, Y.F. A Study on the Feature of Precipitation Concentration and Its Relation to Flood-Producing in the Yangtze River Valley of China. Chin. J. Geophys. 2004, 47, 709-718. [CrossRef]

15. Yang, S.L.; Milliman, J.D.; Xu, K.H.; Deng, B.; Zhang, X.Y.; Luo, X.X. Downstream sedimentary and geomorphic impacts of the Three Gorges Dam on the Yangtze River. Earth-Sci. Rev. 2014, 138, 469-486. [CrossRef]

16. Li, L.; Lu, X.; Chen, Z. River channel change during the last 50 years in the middle Yangtze River, the Jianli reach. Geomorphology 2007, 85, 185-196. [CrossRef]

17. Yin, H.; Li, C. Human impact on floods and flood disasters on the Yangtze River. Geomorphology 2001, 41, 105-109. [CrossRef]

18. Sun, Z.H.; Li, Y.T.; Huang, Y.; Gao, K.C. Fluvial process of sandbars and shoals in branching channels of the middle Yangtze River. J. Hydraul. Eng. 2001, 42, 1398-1406. (In Chinese)

19. Yu, F.; Chen, Z.; Ren, X.; Yang, G. Analysis of historical floods on the Yangtze River, China: Characteristics and explanations. Geomorphology 2009, 113, 210-216. [CrossRef]

20. Zong, Y.; Chen, X. The 1998 flood on the Yangtze, China. Nat. Hazards 2000, 22, 165-184. [CrossRef]

21. Ya, L.; Fei, W.; Yitian, L. Objective river pattern of waterway regulation of goose-head-shaped a nabranching channel in the Middle and Lower Yangtze River. J. Hydraul. Eng. 2015, 46, 443-451. (In Chinese)

22. Li, Z.; Wang, Z.; Jia, Y.; Li, W. Evolution analysis of channel bars in the middle and lower Yangtze River before and after impoundment of three gorges reservoir. Res. Environ. Yangtza Basin 2015, 24, 65-73. (In Chinese) 
23. Lv, L.; Li, Z.; Liu, X. Analysis on River Channel Evolution and Regulation of Ma'anshan Reach of Yangtze River. J. Yangtze River Sci. Res. Inst. 2009, 26, 13-16. (In Chinese)

24. Zhang, J.; Li, J.; Fang, H.; Gu, L.; Shi, J.; Zhu, Q.; Wu, Z. Analysis of flood characteristics of Changiang River basin in Anhui Province of 2016. Yangtze River 2017, 4, 66-69. (In Chinese)

25. The Ministry of Water Resources of the People's Republic of China Promulgated "2016 China Flood and Drought Disaster Bulletin". Available online: http:/ / www.mwr.gov.cn/sj/tjgb/zgshzhgb/201707/ t20170720_966705.html (accessed on 1 July 2018).

26. From Wikipedia. Available online: https://en.wikipedia.org/wiki/1954_Yangtze_River_floods (accessed on 22 September 2018).

27. Xu, N. Detecting Coastline Change with All Available Landsat Data over 1986-2015: A Case Study for the State of Texas, USA. Atmosphere 2018, 9, 107. [CrossRef]

28. Mueller, N.; Lewis, A.; Roberts, D.; Ring, S.; Melrose, R.; Sixsmith, J.; Lymburner, L.; McIntyre, A.; Tan, P.; Curnow, S.; et al. Water observations from space: Mapping surface water from 25 years of Landsat imagery across Australia. Remote Sens. Environ. 2015, 174, 341-352. [CrossRef]

29. Wang, B.; Xu, Y. Sediment trapping by emerged channel bars in the lowermost Mississippi River during a major flood. Water 2015, 7, 6079-6096. [CrossRef]

30. Shi, H.; Gao, C.; Dong, C.; Xia, C.; Xu, G. Variation of river islands around a large city along the Yangtze River from satellite remote sensing images. Sensors 2017, 17, 2213. [CrossRef] [PubMed]

31. Yang, G.; Xiang, H.; Yu, M.; Duan, W.; Tan, L. Variations of low water level and river bed in middle and lower reaches of Yangtze River. Eng. J. Wuhan Univ. 2009, 42, 64-69. (In Chinese)

32. Wang, Z.; Li, H.; Cai, X. Remotely Sensed Analysis of Channel Bar Morphodynamics in the Middle Yangtze River in Response to a Major Monsoon Flood in 2002. Remote Sens. 2018, 10, 1165. [CrossRef]

33. Lou, Y.; Mei, X.; Dai, Z.; Wang, J.; Wei, W. Evolution of the mid-channel bars in the middle and lower reaches of the Changiiang (Yangtze) River from 1989 to 2014 based on the Landsat satellite images: Impact of the Three Gorges Dam. Environ. Earth Sci. 2018, 77, 1-18. [CrossRef]

34. Chen, H.; Wang, J.; Chen, Z.; Yang, L.; Xi, W. Comparison of water extraction methods in mountainous plateau region from TM image. Remote Sens. Technol. Appl. 2004, 19, 479-484. (In Chinese)

35. Bates, P.D.; Horritt, M.S.; Smith, C.N.; Mason, D. Integrating remote sensing observations of flood hydrology and hydraulic modelling. Hydrol. Process. 1997, 11, 1777-1795. [CrossRef]

36. Godoy, M.D.P.; de Lacerda, L.D. River-island morphological response to basin land-use change within the Jaguaribe River estuary, NE Brazil. J. Coast. Res. 2013, 30, 399-410. [CrossRef]

37. Introduction of Fenghuangzhou. Available online: https://baike.so.com/doc/10040802-10542809.html (accessed on 1 July 2018).

38. Introduction of Changshazhou. Available online: https://baike.so.com/doc/7591563-24826976.html\#refff_ 7591563-24826976-1 (accessed on 1 July 2018).

39. Characteristics of the Yangtze River Flood in Anhui Province. Available online: http://www.ahcjj.cn/ contents /169/2835.html (accessed on 1 July 2018).

40. Characteristics and Implications of the Yangtze River flood in 2016. Available online: http:/ / www.cjh.com. cn/pages/2016-10-08/564_189040.html (accessed on 1 July 2018).

41. China Centre for Resources Satellite Data and Application. GF-1. Available online: http://www.cresda.com/ (accessed on 1 July 2018).

42. Terrestrial Observing Satellite Data Service Platform. Available online: http://www.cresda.com/CN/ (accessed on 1 July 2018).

43. Anhui Hydrological Telemetry Information Network. Available online: http://yc.wswj.net/ahyc/ (accessed on 1 July 2018).

44. Lyons, E.A.; Sheng, Y.; Smith, L.C.; Li, J.; Hinkel, K.M.; Lenters, J.D.; Wang, J. Quantifying sources of error in multitemporal multisensor lake mapping. Int. J. Remote Sens. 2013, 34, 7887-7905. [CrossRef]

45. McFeeters, S.K. The use of the Normalized Difference Water Index (NDWI) in the delineation of open water features. Int. J. Remote Sens. 1996, 17, 1425-1432. [CrossRef]

46. Ji, L.; Zhang, L.; Wylie, B. Analysis of dynamic thresholds for the normalized difference water index. Photogramm. Eng. Remote Sens. 2009, 75, 1307-1317. [CrossRef] 
47. Foody, G.M. Status of land cover classification accuracy assessment. Remote Sens. Environ. 2002, 80, $185-201$. [CrossRef]

48. Zhang, Q.; Xu, C.Y.; Becker, S.; Jiang, T. Sediment and runoff changes in the Yangtze River basin during past 50 years. J. Hydrol. 2006, 331, 511-523. [CrossRef] 